\title{
Stoppa's open preperitonealprolene mesh hernioplasty: A critical analysis of operative outcome in bilateral inguinal hernias and its place in present era
}

\author{
Authors \\ Dr Priya Ahire ${ }^{1}$, Dr Nihar Chandak ${ }^{2}$, Dr Gautami Joshi ${ }^{3}$, Dr Shriram Savant ${ }^{4}$, \\ Dr Yugal Pathrabe ${ }^{5}$ \\ ${ }^{1}$ Assistant Professor, Department of Surgery, J. J. Group of Hospitals, Mumbai \\ ${ }^{2}$ Senior Resident, Department of Surgery, J. J. Group of Hospitals, Mumbai \\ 3,4,5 Junior Resident, Department of Surgery, J. J. Group of Hospitals, Mumbai
}

\section{Introduction}

Hernia (Latin, rupture; Greek, bud) defined as protrusion of aviscus through an opening in the wall of the cavity in which it is contained ${ }^{[1]}$. The zone of weakness is the common feature possessed by all hernias by way of which structures can pass through the wall of the cavity which contains them. Out of all the potential hernial sites inguinal area is unequalled in its structural weakness ${ }^{[2]}$. In addition, due to the upright position acquired by man in course of evolution, the inguinal region is subjected to a large part of the weight of mobile intestines, which contributes towards the high incidence of herniation in human beings.

Hernias has been known since evolution of man and the history of hernia is the history of surgery as stated by Jose Felix ${ }^{[3]}$. Many great men have been devising innovative methods to repair hernia surgically. First were the anatomical repairs amongst which bassini's and shouldice's repairs were accepted and followed worldwide. Later the use of prosthesis came into practice. As early as 1900, Phelps, Goepel and Witzel used silver wire braided meshes (known as silver filigrees) ${ }^{[4-7]}$.
These early meshes were far from ideal. During the Second World Warcame the age of the plastics industry. These were polypropylene, polyester and expanded polytetrafluoroethylene (ePTFE), which paved the way for the prosthetic meshes available today ${ }^{[8-10]}$. This drastically decreased the rate of recurrences. With the acceptance of mesh usage, many pioneer surgeons came up with indigenous methods of using it. Then came the question of which plane the mesh is to be placed.

In 1969, Rene Stoppa introduced a procedure that involved the placement of a giant prosthetic mesh in the preperitoneal space deep to the transversalis fascia to cover the myopectinealorifices on both sides $^{[11]}$. The mesh acts as an artificial endoabdominal fascia that prevents the visceral sac extension through the defect. The increased intra-abdominal pressure, the causative factor, presses the mesh against the abdominal wall, becoming a preventive factor for recurrence and herniation through other weaknesses. Stoppa procedure, being a posterior preperitoneal procedure, involves dissection in a plane with no nerves and minimal cord handling, thus avoiding inguinodynia and testicular atrophy ${ }^{[12]}$. 
The conventional Stoppa Repair required extensive dissection of the sub fascial preperitoneal space that necessitated the use of suction drainage. In this study we evaluated our experience regarding the stoppa technique in bilateral inguinal hernia with the use of two small sized mesh of $15 \mathrm{~cm} \times 7 \mathrm{~cm}$ in place of giant prosthetic mesh in view ofpost-operative events and complications during 1 year follow up.

\section{Materials and Method}

The study was conducted at the Surgical Department of Sir J. J. Groups of Hospitals, Mumbai from Jan 2017 to Jan 2019. The primary inclusion criterion in 54 patients were the presence of bilateral inguinal hernia which were managed by Stoppa's open preperitoneal prolene mesh hernioplasty. Even patients with recurrence were included. Patients presenting with unilateral hernia, strangulated hernia, obstructed hernia, with a midline scar from a previous laparotomy and those suffering from hemorrhagic tendency were excluded.

These patients were operated under spinal anaesthesia. Preoperatively patients were catheterised. The lower midline incision was put and the subcutaneous tissue dissected. Incision was made in the anterior rectus sheath in the midline. The underlying recti are separated from each other to reach the preperitoneal space. Dissection progressed laterally under the rectus abdominis muscle and posteriorly to the inferior epigastric vessels. The dissection is continued downward, anterior to the bladder, to the prostatic fossa, and behind the iliopubic ramus in the space of Bogros. The hernia sac is isolated, either distinct from the spermatic cord (in direct inguinal or femoral hernias) or connected to it (in indirect inguinal hernias). The preperitoneal cleavage is then continued to expose the external iliac vessels and laterally along the psoas muscle and upto the bilateral anterior superior iliac spine. Parietalization of the components of the spermatic cord is undertaken. Triangle of Doom and Triangle of Pain visualized and safe guarded.
Small peritoneal tear were repaired with $3^{\text {ee }} 0$ vicryl sutures. Two small sized mesh of $15 \mathrm{~cm}$ $\mathrm{x} 7 \mathrm{cmis}$ placed extending from anterior superior iliac spine from both sides to pubic symphysis. The two meshes are hitched in the centre with non-absorbable suture together with the posterior aspect of pubic symphysis to avoid mesh displacement. Closure was done in layers. No drains were inserted. Operation time was noted. In case of large hernial sacs, external compression was given over inguinal region.

Post-operative course in the hospital was noted for pain and other early post-operative complications. Patients were evaluated on POD 10, 1 month, 6 months, 9 months and 12 months after surgery for minor complications, recurrence and chronic groin pain.

Quantitative data is presented with the help of mean and standard deviation. Results were graphically represented where deemed necessary. Appropriate statistical software, including but not restricted to MS Excel, SPSS version 20 were used for statistical analysis. Graphical representation was done in MS Excel 2013.

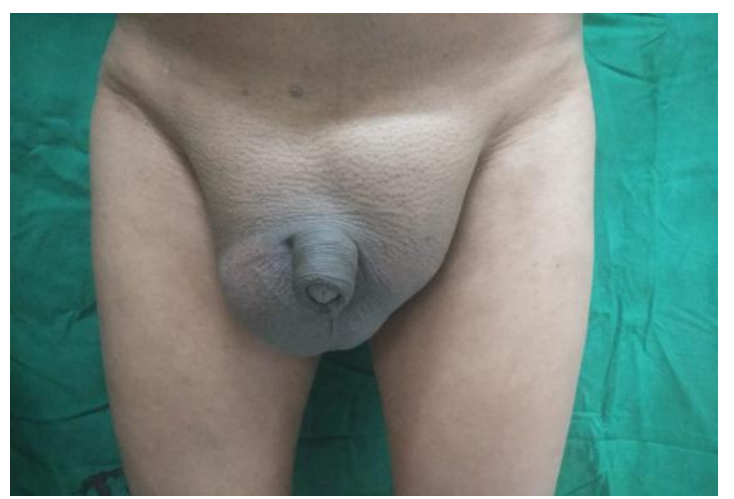

Fig 1 Bilateral Inguinal Hernia

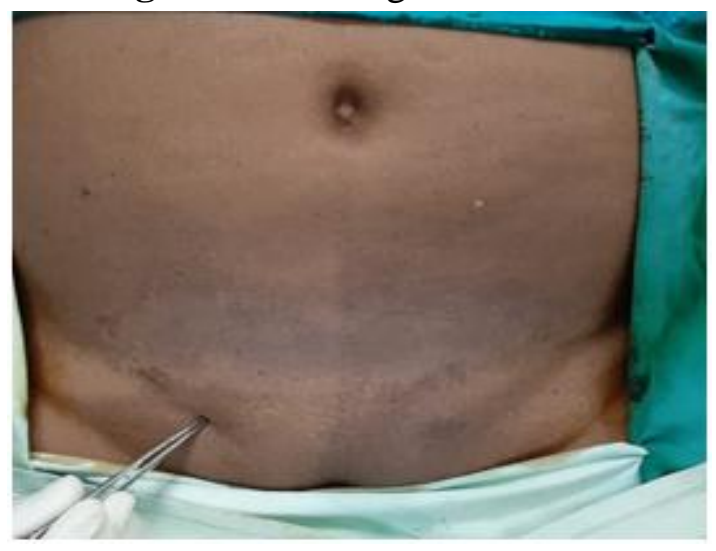

Fig 2- Case of bilateral inguinal hernia with right recurrent inguinal hernia 


\section{JMSCR VoI||07||Issue||04||Page 517-524||April}

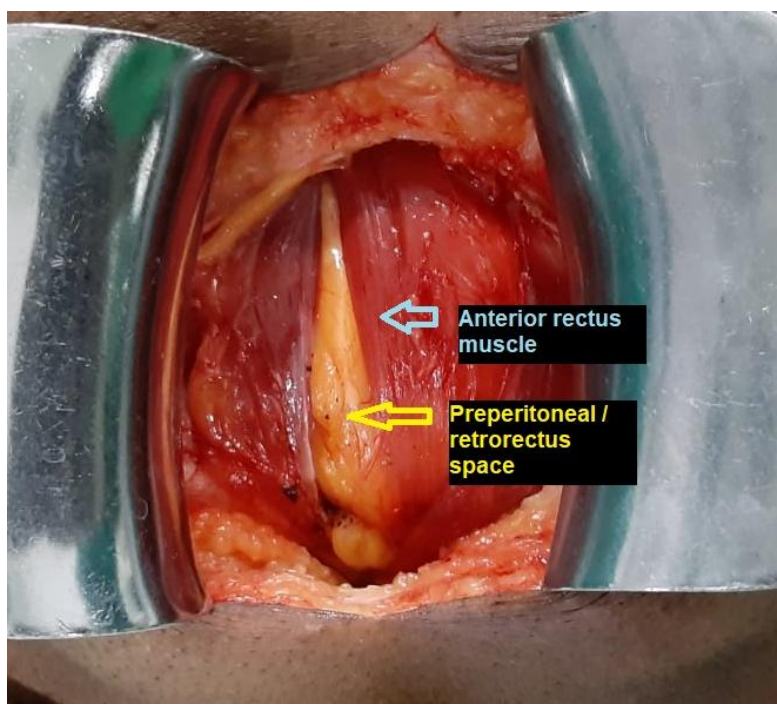

Fig 3 Preperitoneal (retrorectus) space of dissection

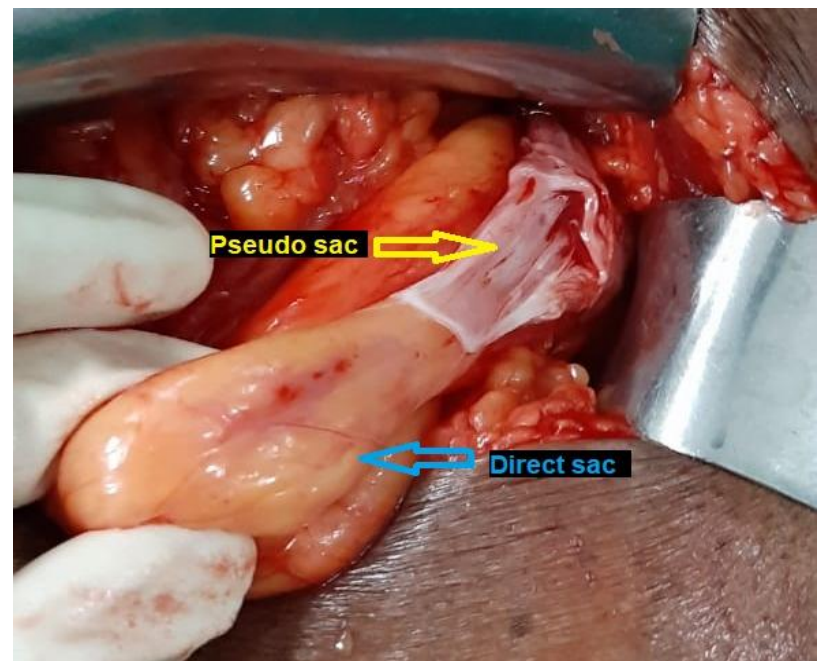

Fig 4 Dissection of direct sac from its pseudo sac

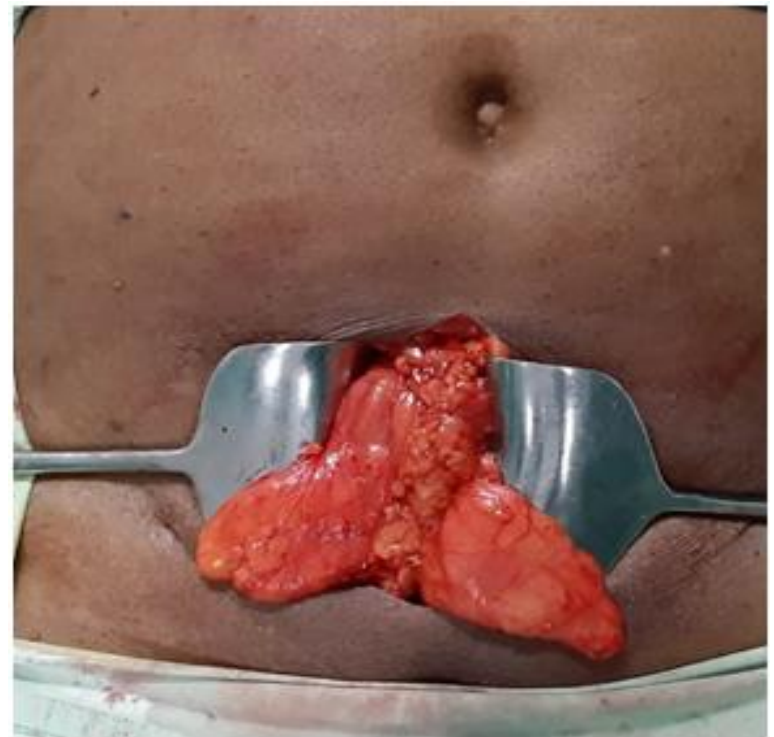

Fig 5- Bilateral direct sacs dissected

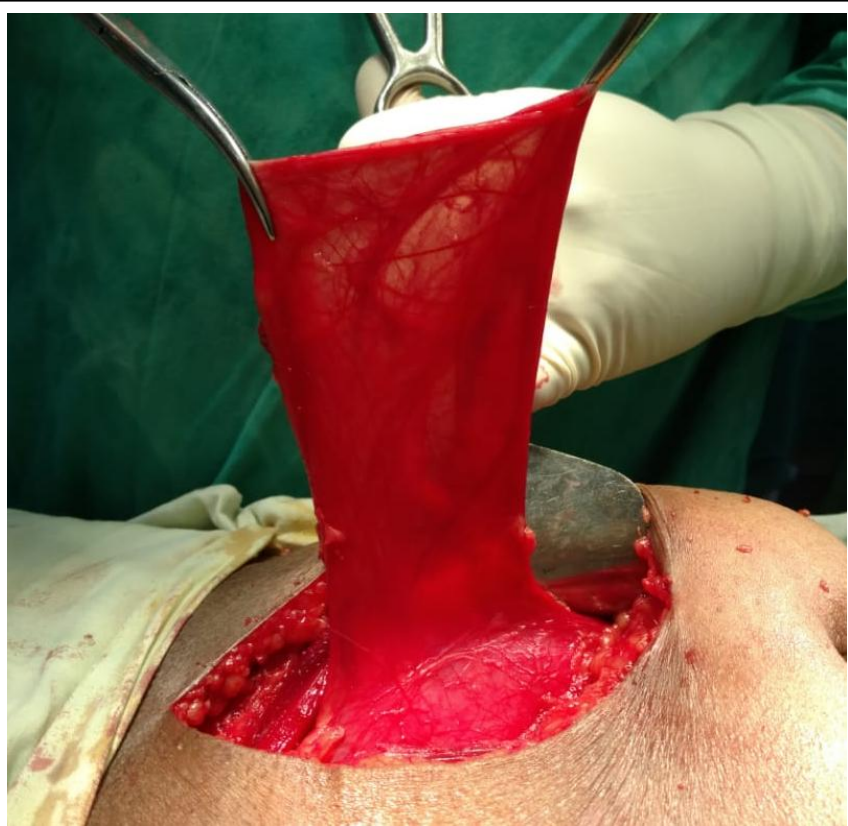

Fig 6- Dissected huge direct sac

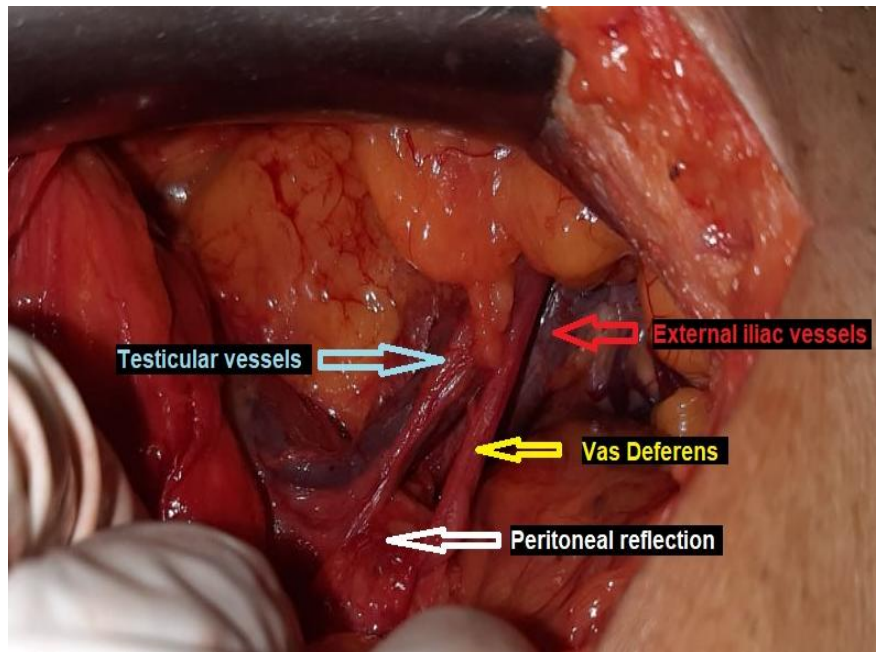

Fig 7- Triangle of Doom

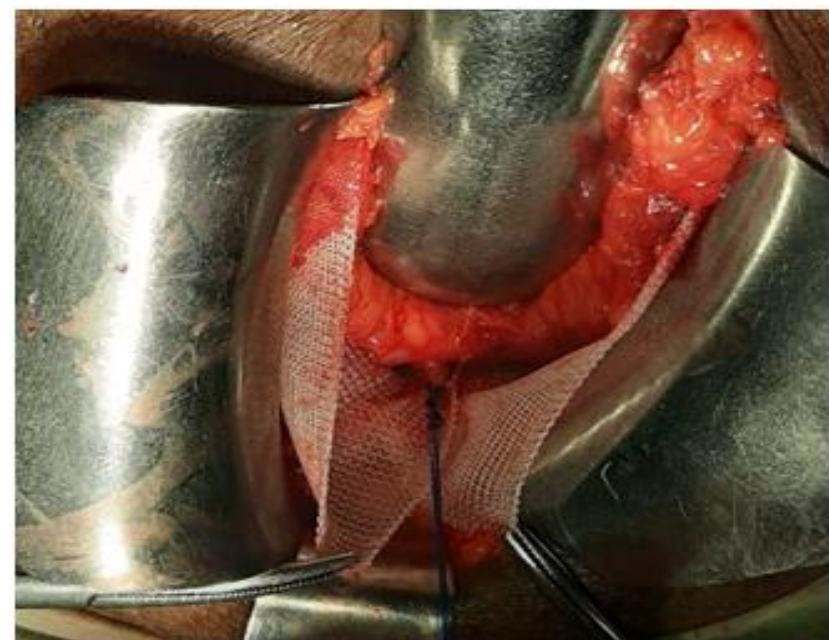

Fig 8- Two small meshes of size $15 \mathrm{~cm} \times 7 \mathrm{~cm}$ hitched together with posterior aspect of pubic symphysis 


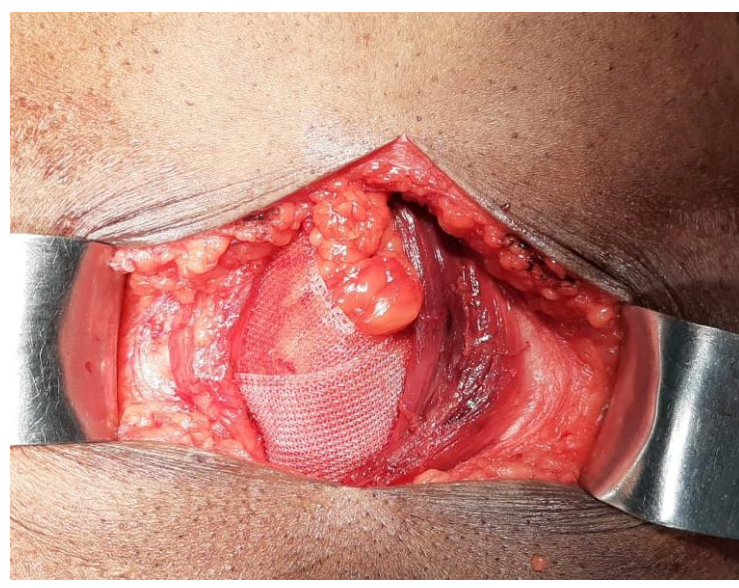

Fig 9- Overlapped mesh placement

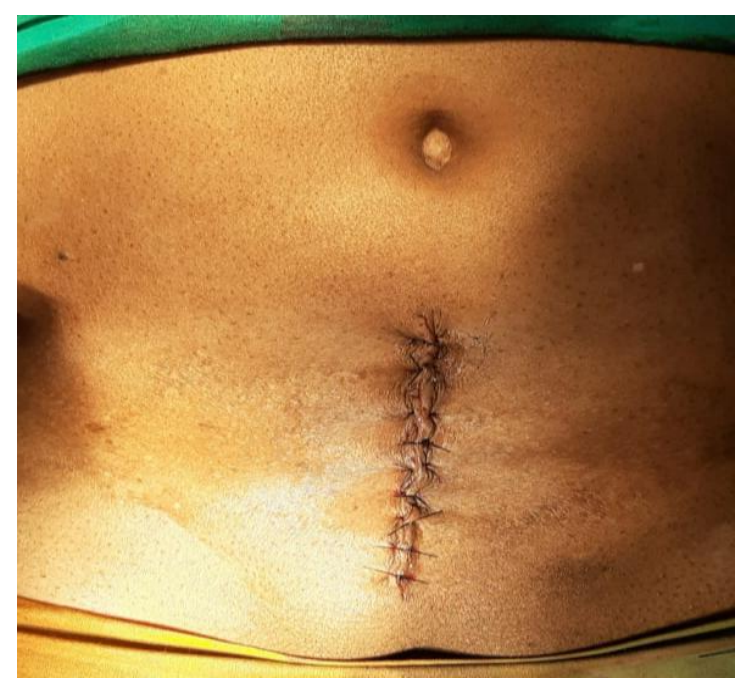

Fig 10- Sutured lower midline incision

\section{Results}

A total of 54 patients were enrolled in the study. All were males. The age of patient varied from 31 years to 85 years, with a mean age of 56.3 years. All patients underwent Stoppa repair without drainage procedure under spinal anaesthesia. Incision used was lower midline incision. Out of these patients, the types of hernia involved are shown in Table 1. There were 3 cases of recurrent unilateral inguinal hernia who were previously operated by inguinal incision; Bassini's or Lichtenstein's, now presenting as bilateral inguinal hernia.

Average time taken during surgery was 47 mins, minimum time being 32 mins and maximum being 72 mins. In initial 18 cases, average duration of surgery was 63.3 mins while last 18 cases average operative time duration was 34.5 mins. There was a significant reduction in operative time over a period. The mean hospital stay duration was 3.3 days.

The patient morbidity was analysed over a follow up duration of 1 year post operatively. This included seroma, haematoma, infection, neuralgia, recurrence and general complications (Table 2).Superficial wound infection had developed in 1 case where the suture line had to be laid open and secondary suturing was done later without mesh excision.

Single recurrence was observed in initial 18 cases and no recurrences were seen further. The single recurrent bilateral inguinal hernia patient who had come after one year, was re-operated by Lichtenstein's hernioplasty.

Table 1 Type of Hernias

\begin{tabular}{|l|c|c|}
\hline Type of Hernia & Right side & Left side \\
\hline Direct & 33 & 32 \\
\hline Indirect & 16 & 14 \\
\hline Pantaloon/ Combined & 05 & 08 \\
\hline Total & 54 & 54 \\
\hline
\end{tabular}

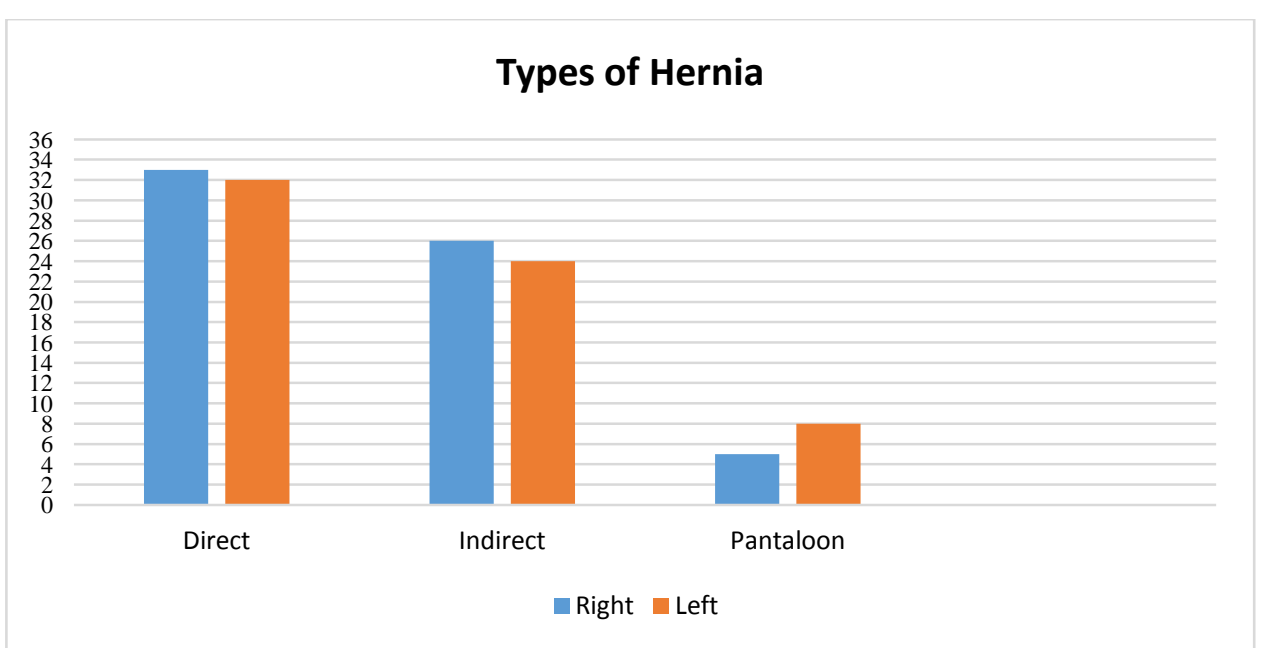


Table 2 Mean operative time for every 1/3rd no. of cases

\begin{tabular}{|l|c|}
\hline No. of cases & Mean operative time (mins) \\
\hline 1 to 18 cases & 63.3 mins \\
\hline 19 to 36 cases & $43.4 \mathrm{mins}$ \\
\hline 37 to 54 cases & 34.5 mins \\
\hline
\end{tabular}

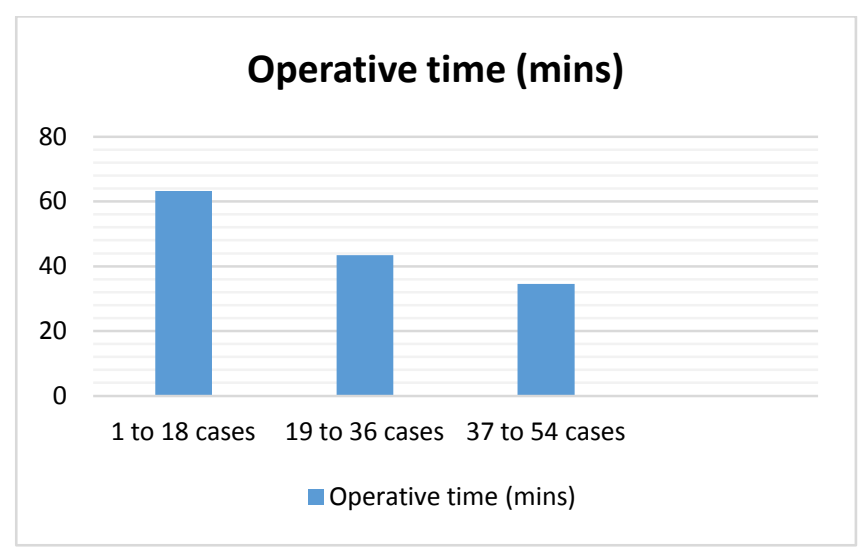

Table 3 Post-operative Morbidity

\begin{tabular}{|l|c|c|}
\hline Complications & No. of cases & Percentage \\
\hline Seroma & 3 & $5.5 \%$ \\
\hline Superficial wound infection & 1 & $1.8 \%$ \\
\hline Neuralgia & 1 & $1.8 \%$ \\
\hline Recurrence & 1 & $1.8 \%$ \\
\hline Mortality & 0 & $0 \%$ \\
\hline Total & $6 / 54$ & $11 \%$ \\
\hline
\end{tabular}

No. of cases with complications

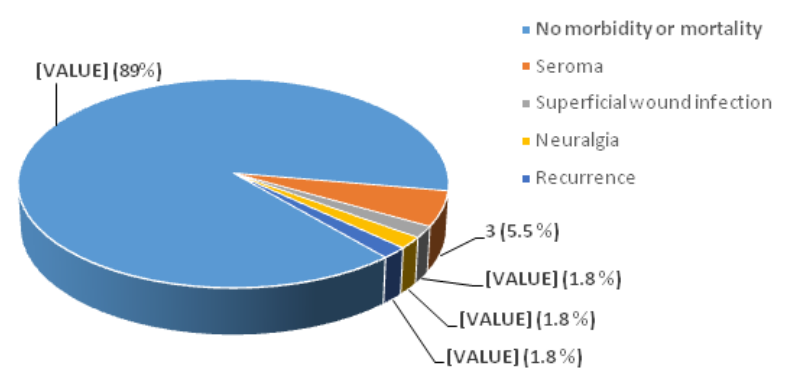

\section{Discussion}

Hernias have always proved to be challenging to the surgeons due to its complex anatomy and variable presentation. Inguinal hernias represent $75 \%$ of all hernias ${ }^{[13]}$. It has a disabling affliction with a lifetime prevalence of $25 \%$ in men and $2 \%$ in women ${ }^{[14]}$. The Stoppa procedure utilizes the many advantages of the preperitoneal approach in inguinal hernia repair. The replacement of the endo abdominal fascia seals the inguinal, femoral and obturator canals as well as all other potential sites of weakness in the lower abdomen. It has many advantages, particularly in cases of recurrent or bilateral inguinal hernias. A key feature of Stoppa's repair is the application of Pascal's principle in mesh placement that reinforces the lower abdominal wall with a welldesigned anatomical approach that does not disturb groin structures, even in cases that were dissected before ${ }^{[15]}$. Miller ${ }^{[16]}$ and colleagues demonstrated that the simultaneous repair of bilateral inguinal hernias is safe and does not result in an increased recurrence rate.

We studied 54 male patients. Mean age in our study was 56.3 years whereas in a study by Ahmed $\mathrm{M}$ et $\mathrm{al}^{[17]}$ it was 54 years. Out of 54 patients we included in the study,51 (94.4\%) had primary bilateral hernia, $3(5.6 \%)$ had recurrent unilateral hernia with contralateral primary hernia. In study by Ahmed $\mathrm{M}^{[17]}$, patients included were eight patients $(27 \%)$ with primary bilateral inguinal hernia. Sixteen (53\%) had a unilateral recurrent hernia with contra lateral primary hernia. Six $(20 \%)$ had a bilateral inguinal hernia with unilateral recurrence.

The use of polypropylene mesh, instead of polyester as described originally by Stoppa, has not changed the results recorded in comparison to the original description. The results are similar to other studies that have also used this type of mesh ${ }^{[18]}$. Polyester mesh is used very infrequently outside of France ${ }^{[18]}$.

The operative time has decreased significantly from the average time of $63.3 \mathrm{~min}$ in initial 18 cases to less than $35 \mathrm{~min}$ in last 18 cases, with $66.6 \%$ of the cases in less than $45 \mathrm{~min}$. This was significantly less compared to the time required for bilateral Lichtenstein's hernioplasty ${ }^{[19,20]}$. The mean hospital stay duration was 3.3 days.

Since the wide spread acceptance of tension free mesh hernioplasty, there have been reports of several complications like seroma, haematoma, wound infections, wound dehiscence and mesh infection. As far as adverse effects were concerned we had almost comparable values with 
other studies. Seroma occurred in 3 patients, Neuralgia was present in 1 patient and superficial wound infection in one for which the suture line had to be laid open. The organism isolated was Staphylococcus. Patient was managed with dressings using hydrogen peroxide and betadine/ Edinburgh University Solution (EUSOL). Secondary suturing was done later without excision of mesh. The case was successfully managed by above measures and no long term morbidity was observed. No patient developed an infected mesh or abscess. So a total of $11 \%$ patients developed post op complications. Stoppa has reported an infection rate of $12 \%$ and none of prosthesis required removal ${ }^{[21,22]}$.

In all of our cases, two small sized $(15 \mathrm{~cm} \times 7 \mathrm{~cm})$ polypropylene mesh were used instead of giant prosthetic mesh as originally devised by Rene Stoppa. This reduced the overall cost of the procedure. Only a single recurrence was observed $(1.8 \%)$ in initial 18 cases and no recurrences were seen further. This is comparable to series by Maghsoudi $\mathrm{H}^{[23]}$, having the $0.85 \%$ (2 of 234) of recurrence rate. According to Stoppa, recurrences should be very low with this technique [24, ${ }^{25]}$.Recurrence rates reported by Rene Stoppa ${ }^{[21]}$ was $2-3.3 \%$ in his initial article and 0.5$1.1 \%$ in later articles. Studies state that in Stoppa's repair, the recurrences are mostly in first 6 months and more likely due to technical failures like small mesh size, splitting of mesh, wrong placement, inadequate dissection, inadequate mesh over-lap fixation, prosthesis folding or twisting or missed hernias. In our case, the recurrence was due to mesh migration, missed indirect component and persistent etiological factors like constipation and smoking. The single recurrent bilateral inguinal hernia patient who had come after 6 month, was re-operated by Lichtenstein's hernioplasty.

We have seen that the experience acquired by surgeons who began to practice the Stoppa technique in our department has contributed to proper performance of this technique. The procedurehas involved a learning curve due to the better understanding of the anatomy and the technique with each case thereby reducing the operative time and rate of recurrence and other complications. In agreement with other authors ${ }^{[26]}$, we consider that performance of 20-25 cases is suitable for the Stoppa technique.

Moreover, learning about this approach allows the surgeons involved to be introduced to laparoscopic extraperitoneal hernioplasty with greater ease and better results ${ }^{[27,28]}$. Laparoscopic hernioplasty (TAPP) or TEP also referred to as "laparoscopic Stoppa" can provide advantages in terms of reduction of total morbidity, inguinal paresthesis, chronic pain and hospital stay.

\section{Conclusion}

Stoppa's open preperitoneal prolene mesh hernioplasty provides certain inherent advantages to the surgeon.-

- This procedure avoids reopening through distorted anatomy in cases of recurrent/multirecurrent hernias.

- Follows pascal's principle to hold the mesh in place without tension.

- Permits inspection of all potential abdominal hernia sites- inguinal, femoral, obturator.

- Reduces the risk of nerve injury, neuralgia, orchitis, testicular atrophy and chronic pain which are potential medico legal complications, found frequently in other inguinal herniorrhaphies.

- This space is a virgin space typically intact during repair of recurrent hernias which greatly facilitates the procedure.

The use of two small sized polypropylene mesh; instead of giant prosthetic mesh as devised originally by Stoppa in its GPRVS technique (Giant Prosthetic Reinforcement of Visceral Sac); showed similar results with respect to operative time, recurrence rate and other long term complications. But instead; it significantly reduced the cost of the procedure as procured by two small sized polypropylene meshin comparison to a giant prosthetic mesh. 
In conclusion, we believe that Stoppa's procedure is a very good technique to repair bilateral inguinal hernia, has the benefit of mesh in preperitoneal position without disadvantages of a laparoscopic approach and is indicated when there is no laparoscopic facilities or cost restraints; and when patients have general anaesthetic or laparoscopic contra indications ${ }^{[29]}$.

\section{References}

1. Read RC. Basic features of abdominal wall herniation and its repair. Shackelford's surgery of the alimentary tract. 4ed. George D. Zuidema. 1996.

2. Nyhus LM, Wantz GE. Hernias and surgery of the abdominal wall. Springer Science \& Business Media; 2012 Dec 6.

3. Patino JF. A history of the treatment of hernia. In: Nyhus LM, Condon RE. Hernia, 4th edition. Philadelphia. J.B.Lippincott. 1995;03-06.

4. Goepel R. Uber die Verschliessung von BruchpfortendurchEinheilunggeflochtener fertigerSilberdrahtnetze. Zentralbl. Chir. 17, 3 (1900).

5. Perry HB. Implantations of silver filigree for cure of large ventral hernia; report of two cases. Boston Med. Surg. J. 151, 2 (1904).

6. Witzel O. Uber den Verschluss van Bauchwunden und Bruchpforten durch versenkte Silberdraht netze. Zetralbl Chir. 27, 3 (1900).

7. Phelps A. A new operation for hernia. NY Med. J. 60, 291 (1894).

8. Usher FC, Wallace SA. Tissue reaction to plastics; a comparison of nylon, orlon, Dacron, Teflon, and Marlex. AMA Arch. Surg. 76(6), 997-999 (1958).

9. Usher FC, Ochsner J, Tuttle LL Jr. Use of marlex mesh in the repair of incisional hernias. Am. Surg. 24(12), 969-974 (1958).

10. Adloff M, Arnaud JP. Surgical management of large incisional hernias by an intraperitoneal Mersilene mesh and an aponeurotic graft. Surg. Gynecol. Obstet. 165(3), 204-206 (1987).

11. Stoppa RE. Wrapping the visceral sac into a bilateral mesh prosthesis in groin hernia repair. Hernia. 2003 Mar 1;7(1):2-12.

12. Read RC. Recent advances in the repair of groin herniation. Current problems in surgery. 2003 Jan 1;40(1):13-79.

13. Abramson JH, Gofin J, Hopp C, Makler A, Epstein LM. The epidemiology of inguinal hernia. A survey in western Jerusalem. Journal of Epidemiology \& Community Health. 1978 Mar 1;32(1):59-67.

14. Manzar TS. Inguinal hernia incidence, complications and management. JCPSP 1992; 2: 7-9.

15. Rodrigues Jr AJ, Jin HY, Utiyama EM, Rodrigues CJ. The Stoppa procedure in inguinal hernia repair: to drain or not to drain. Revista do Hospital das Clínicas. 2003;58(2):97-102.

16. Miller AR, van Heerden JA, Naessens JM, O'Brien PC. Simultaneous bilateral hernia repair. A case against conventional wisdom. Ann Surg. 213:272-276; 1991.

17. Ahmed M, Shahid M. EARLY POSTOPERATIVE COMPLICATIONS OF STOPPA'S REPAIR. Pak Armed Forces Med J Jun 2008;58(2):141-6

18. Gonzalez R, Ramshaw BJ. Comparison of tissue integration between polyester and polypropylene prostheses in the preperitoneal space/Discussion. The American Surgeon. 2003 Jun 1;69(6):471.

19. Stoppa RE, Warlaumont CR, Verhaegue PJ (1986) Prosthetic repair in the treatment of groin hernias. IntSurg 71: 154-158

20. Beets GL, Van Geldere D, Baeten CG, Go PM (1996) Longterm results of giant prosthetic reinforcement of the visceral sac for complex recurrent inguinal hernia. $\mathrm{Br} \mathrm{J}$ Surg 83:203-206. 
21. Stoppa RE. The treatment of complicated groin and incisional hernias. World J Surg. 1989;13(5):545-54

22. Me Greevy JM. Groin Hernia and Surgical truth. Am J Surg 1998; 176: 301-4

23. Maghsoudi H, Pourzand A. Giant prosthetic reinforcement of the visceral sac:theStoppa groin hernia repair in 234 patients. Ann Saudi Med. 2005;25(3):228232.

24. Stoppa R (1999) Groin hernia repair by bilateral extraperitoneal mesh prosthesis. In: Zurker M, Kark AE, Wantz GE (eds) Surgical management of abdominal wall hernias, vol 16. Martin Dunitz Ltd, London, pp 203-214

25. Solorzano CC, Mintez RM, Childers TC, Kilkenny JW, Vauthey JN (1999) Prospective evaluation of the giant prosthetic reinforcement of the visceral sac for recurrent and complex bilateral inguianl hernias. Am J Surg 177:19-22

26. Fernandez-Lobato R, Tartas-Ruiz A, Jiménez-Miramón FJ, Marín-Lucas FJ, de Adana-Belbel JC, Esteban ML. Stoppa procedure in bilateral inguinal hernia. Hernia. 2006 Apr 1;10(2):179-83.

27. Katkhouda N, Campos GM, Mavor E, Trussler A, Khalil M, Stoppa R (1999) Laparoscopic extraperitoneal inguinal hernia repair. A safe approach bases on the understanding of rectus sheath anatomy. SurgEndosc 13(12):1243-1246

28. Weber A, Gareiz D, Cueto J (1999) Stoppa-type laparoscopic repair of complex groin defects. Surg Laparosc Endosc 9(1): 14-16

29. Koc M, Aslar AD, Yoldas A, Ertan T, Kilic M, Gocmen E (2004) Comparison of quality-of life outcomes of Stoppa vs bilateral Lichtenstein procedure. Hernia $8(1): 53-55$ 